\title{
Unravelling Children’s Perceptions of Parental Differential Treatment ${ }^{*}$
}

\author{
Rozemarijn Jeannin, Karin Hannes, Karla Van Leeuwen \\ KU Leuven, Leuven, Belgium
}

\begin{abstract}
Within-family differences in parenting (PDT (parental differential treatment)) can be accompanied by children's perceptions of parental favoritism. Perceptions of fairness of PDT are essential, however, little is known on how children legitimize PDT. We used focus groups and individual interviews to explore children's $(N=16)$ differential experiences. Interviews were transcribed and analyzed using a hybrid deductive-inductive approach. Questions targeted: (1) domains of PDT; (2) explanations of PDT; and (3) considerations of fairness. The results show that siblings gave examples of differential affection, control, time involvement, privileges and household responsibilities, but additionally expressed responsibilities in care of each other. Three explanatory categories were added to responses of previous child samples: birth order, sibling relationship quality and biological relatedness. Fairness-considerations comprised a cognitive and emotional component and moderating factors. Equity was obtained through parents' responsiveness to child and family characteristics and through compensating strategies, such as turn-taking. Children are able to acknowledge and legitimize PDT. Parents' differentiation does not preclude siblings' perceptions of equal treatment.
\end{abstract}

Keywords: PDT (parental differential treatment), favoritism, perceptions, children, qualitative research

\section{PDT (Parental Differential Treatment) and the Relation With Child Outcome}

Previous research examined how environmental issues, such as experiences with parents and peers lead to differences in children. However, children living in the same family do not differ more from each other than those belonging to different families when genetic factors are taken into account. Parenting effects shared by siblings within the family seem to be limited (Plomin, Asbury, \& Dunn, 2001). Thus, it might be advisable to take a different view on the effects of parenting, by considering parenting as a non-shared environmental factor. According to this view, researchers investigated how parenting can operate differently towards children reared in the same family. Parenting effects are investigated towards each child separately, and not as a general family characteristic.

In the mid-80s, Plomin and Daniels (1987) proposed the concept of PDT (parental differential treatment)

\footnotetext{
*Acknowledgements: The authors would like to express their gratitude to their schools and families who participated in this study. Also, the authors want to thank Nadine Aerts for assisting in the data analysis of the qualitative data.

Rozemarijn Jeannin, Parenting and Special Education Research Unit, Faculty of Psychology and Educational Sciences, KU Leuven.

Karin Hannes, Methodology of Educational Sciences Research Unit, Faculty of Psychology and Educational Sciences, KU Leuven.

Karla Van Leeuwen, Parenting and Special Education Research Unit, Faculty of Psychology and Educational Sciences, KU Leuven.
} 
as a non-shared environmental factor, stating that siblings' differential experiences within the family can result in differences in child outcome. Children not only respond to how they are treated by their parents (absolute parenting), but also to how this treatment is perceived in relation to their siblings (Tamrouti-Makkink, Dubas, Gerris, \& van Aken, 2004).

According to the individual development hypothesis, concurrent PDT can reflect the normative developmental patterns of parent-offspring affection or control of two siblings who differ in developmental needs (Shanahan, McHale, Crouter, \& Osgood, 2007). For example, parents adjust their parenting strategies according to the age of their children (Jenkins, Rasbash, \& O’Connor, 2003). On the other hand, parents can differ in their sensitivity towards their children's needs (Fearon, van IJzendoorn, Fonagy, Bakermans-Kranenburg, Schuengel, \& Bokhorst, 2006). They carry along their own experiences with parents and siblings (Donley \& Likins, 2010). Furthermore, children can differ in what they consider equal treatment (McGillicuddy-De Lisi, De Lisi, \& Van Gulik, 2008). Thus, PDT can also reflect parental favoritism.

Children start making social comparisons very early in life (Dunn \& Munn, 1985). Social comparison processes play an important role in middle childhood (McGuire, Dunn, \& Plomin, 1995). In adolescence, children can acquire more tolerance of PDT, due to de-identification processes between siblings (Feinberg, McHale, Crouter, \& Cumsille, 2003), more sophisticated cognitive levels and an increased importance of peer relationships compared to parent-child relationships (Crick \& Dodge, 1994).

\section{Children's Perceptions of PDT}

Children's perceptions of PDT are mainly measured with the SIDE (sibling inventory of differential experience) (Daniels \& Plomin, 1985), which taps differences in parental "affection" and "control", the traditional dimensions of parenting, within their own family (Schaefer, 1959). Research with children revealed additional domains of differential parenting, next to the traditional dimensions of parenting (McHale, Updegraff, Jackson-Newsom, Tucker, \& Crouter, 2000; Tucker, McHale, \& Crouter, 2003). In a qualitative pilot study, children were asked what it was like to be the oldest or youngest in the family and reported on differential "chore allocation/household responsibilities", differential "privileges" and differential "time involvement”. In a subsequent quantitative study, sex and sex-typed personal qualities were related to parents' affection, discipline and time involvement, and girls took a larger stake in household chores. Age and birth order were related to privileges and chores (Tucker et al., 2003). The samples consisted of children in nuclear families.

The amount of PDT differs according to family type. O’Connor, Dunn, Jenkins, and Rasbash (2006) conducted multilevel analyses with measures of PCR-Q (Parent-Child Relationships Questionnaire) in biological, single-mother, stepfather and complex/stepmother stepfamilies. Parent-child relationships in step-families appear to be more differential than parent-child relationships in biological or single-parent families. Parents are more engaged in biological parent-child relationships and take on a larger stake in parenting towards their biological children. This may induce more warmth as well as more conflict in biological parent-child relationships, as shown in previous studies, whereas non-biological relationships are more distant (O’Connor et al., 2006; Thomson, McLanahan, \& Curtin, 1992). Also, children with developmental needs, such as mental retardation, can evoke parental differential treatment (McHale \& Pawletko, 1992).

Differences in parenting can go together with perceptions of "favoritism", which can evoke negative 
emotional responses. Thompson and Halberstadt (2008) interviewed children about instances in which they experienced jealousy because of a (threat of) loss of parental attention in favor of their sibling, and identified four jealousy-evoking situations of PDT: (1) attention to the sibling by giving gifts; (2) taking the sibling's side in conflict; (3) spending more time with the sibling; and (4) attention to the sibling because of the sibling's ability or talent.

Equal treatment is highly valued in Western society (Parsons, 1974), and equal treatment is the modal response when children are questioned about PDT in their own family (Kowal \& Kramer, 1997), even though alternative measures of PDT support differentiation in parenting strategies (Dunn, Stocker, \& Plomin, 1990). Examples of PDT can be more easily accessible when children do not have to appeal to their own family context. Further, it is assumed that children prefer to receive more affection and less control than their siblings, although this view disregards beneficial aspects of parental control (Sheehan \& Noller, 2002).

Thus, qualitative research indicates that parents adapt their strategies in line with developmental differences among the children and that parenting differences can be accompanied by social-affective responses. However, perceptions of domains of PDT are restricted to nuclear families with normally developing children, and reports of favoritism might be restricted in previous research as children who report PDT in their family deviate from a societal norm. Reflections on PDT can be more easily accessible in a general family context, as these are not blurred by loyalty issues. Further, little is known on how differences in parenting behavior are translated into perceptions of favoritism.

\section{Fairness as a Link Between PDT and Child Outcome}

Children distinguish between unfair and fair differential treatment by parents and this is often more strongly related to child outcome than the amount of PDT (Kowal, Kramer, Krull, \& Crick, 2002; Kowal, Krull, \& Kramer, 2004). McHale and colleagues noted that perceptions of equal treatment are intertwined with perceptions of fairness, as children who view differences as fair, might underestimate the amount of differentiation (McHale, Crouter, McGuire, \& Updegraff, 1995). Thus, it is important to characterize children's explanations of PDT, rather than solely focusing on the amount or direction of PDT.

Equal treatment as an approximation of fair differential treatment can be gathered within distributive justice reasoning. Research on distributive justice (Deutsch, 1975) indicates that children can allocate (material) resources based on principles of "equity", "need" or on "equality”. Applied on parental resources, a focus on equality would imply that children only look at their parents' "behavior", which can be equal or unequal towards the siblings. On the other hand, children who use principles of equity and benevolence, consider "child”, "parent” or "context” characteristics to which their parent's behavior can be adjusted to. In distributive justice research, children in middle childhood more often base their judgments on the efforts and productiveness of the characters (equity-rule) and allocate resources based on the neediness of characters (benevolence-rule), whereas younger children judge the equality principle as more fair than older children and are more likely to look at salient characteristics, such as age (Thomson \& Jones, 2005). Also, social relationships among the characters to whom the allocations are made, influence distributive justice reasoning. The benevolence-rule is favored on top of the productivity-based rule for family members (McGillicuddy-De Lisi et al., 2008) and children highly favor the equality rule when it concerns siblings (Thomson \& Jones, 2005).

There is a dearth of studies that explore the application of distributive justice within a socially relevant 
context. To the best of our knowledge, distributive justice reasoning in socially relevant family contexts was only applied on the division of household tasks among siblings in the study of Thomson (2007). To children in early adolescence, six hypothetical vignettes were presented, differing in the amount of time or the types of tasks, according to the distributive justice rules of "equality", "equity" ("reward for work" - children that worked outside the home and contributed a wage) and "need/benevolence" (need to stay at school-competition between household tasks and schoolwork). Fairness-ratings were gathered and open-ended justifications were coded. The equality rule was rated as fairer than both the equity rule and the benevolence rule. Also, "turn-taking" appeared to be a criterion, in which siblings took turns in performing a certain task. However, turn-taking did not always balance out differences. This study exemplifies the importance of using everyday situations in research on distributive justice, but did not explore other domains of PDT, such as parental affection and control.

Kowal and Kramer (1997) identified several attributions of children with regard to differential affection and control that are in line with the principles of distributive justice reasoning, using a qualitative study design. They interviewed children in intact families about their own experiences of PDT and their explanations for these differences. In general, children reported differential parenting as fair. Eleven content attributions were identified, of which five were retrieved for further analyses: "sibling's needs", "personal attributes", such as "personality”, "sibling-driven behavior", "family alliances” and "age”. Attribution to the sibling's needs was associated with more harmonious sibling relationships. They did not examine if some explanations were considered fairer than others. This leaves several questions unanswered. For example, why is referring to the sibling's needs related to better sibling relationship quality? Is this category considered fairer, and would this translate into better family relationships and child well-being in general? If so, why is this explanation fairer than others? Or is a different process at work, specific for the link between siblings' needs and their relationship with each other? If we want to help parents explain PDT to their children in a way that children view PDT as fair, we need to know which explanations to choose and capture the principles children use to make these judgements.

\section{Research Aims}

It is questionable whether the current questionnaires of children's perceptions of PDT grasp all aspects relevant in PDT, because not all domains of PDT are captured simultaneously in the studies using questionnaires and because inconsistencies exist between measurements. Firmly hosted in existing, primarily quantitatively oriented literature, it is doubtful that these studies have really captured the real life experience of the children. Few in-depth qualitative research studies have been conducted, with several gaps still to be filled. Previous qualitative research projects on the domains of PDT have mainly focussed on age-difference as an important aspect of PDT. Further, they did not address PDT in a general family context, but targeted the child's personal experiences within the family. In addition, children from blended families have seldom been included in the samples. As a consequence, additional domains and explanations for PDT may be found, when these children are included in the sample population. Maximizing the variation in the sample would also contribute to a more complete theoretical framework on influencing factors of PDT and where and when needed would facilitate a comparison between children from different family types.

As fairness seems to be a key point in the relation between PDT and child outcome, we aim to explore the principles of fairness in order to create a theoretical framework from which hypotheses can be drawn on the 
relationship between within-family parenting differences on the one hand, and perceiving these differences as a reflection of parental favoritism on the other hand. Furthermore, the framework can be used to assist parents in explaining PDT to children, in a way that increases child's comprehension and contributes to the quality of the family relationships. The scant literature on distributive justice within the family indicates that family situations enhance the importance of the equality-principle, at the expense of principles of equity, but only differential division of household tasks has been explored. The present study aims to better understand children's conceptualisation of "equal treatment" versus "differential treatment" on multiple domains of PDT, by exploring the characteristics of fair and unfair demonstrations of parental differentiation. Thus, children's explanations will not only be described, but will also be framed within distributive justice reasoning.

\section{Method}

\section{Participants and Setting}

We conducted eight individual interviews with children in middle and late childhood, age nine to 13 (elementary and secondary school) from four different families (three nuclear families and one blended family). Three of them were boys and one girl had a sibling with a physical disability (see Table 1). Children had one to three siblings. Families were contacted through a snowball procedure in which participating families could give contact information of other families who might be interested to participate. Because we intended a varied scope of perceptions, we used maximum variation in child and family characteristics as a selection criterion in our purposeful sample. Interviews were conducted with all the resident children in the selected families that had reached the minimum age of eight. The interviews took place at the home environment. Parental and child informed consent were gathered.

We used method triangulation as a means to increase the validity of our study and additionally conducted two focus groups. This method has several advantages. Focus group interviewing overcomes issues of literacy skills in participation and is known to facilitate research in child populations (Kennedy, Kools, \& Krueger, 2001). A large number of perceptions on a given topic can be gathered in a relatively short time frame. Participants are less pressured to provide individual responses, which protects them to reveal more personal information than they intend to. Children can build on each other's exclamations and have to explain their statements to each other. In this way, in-depth information on the cognitions and feelings on the research topic can be collected, within the wordings and frame of the population under investigation (Morgan, 1996).

The age range of the children in the focus groups was between nine and 11 years old and family size ranged to six children. In line with the recommendations of Kennedy et al. (2001) to assign children to groups with a homogeneous developmental level, we separated children between nine and 10 years old (3rd and 4th years of elementary school) from children of 11 years old (5th and 6th grades). The first focus group consisted of two boys and two girls aged from nine to 10. Family type was single parent in one child. The second group consisted of four girls, aged 11. Family type was blended in one child (see Table 1).

Participants for the focus groups were recruited via Flemish elementary schools. Seven schools were contacted, and two schools participated, each providing one focus group. A minimum of two groups addressing the same topic is recommended (Morgan, 1996). Selection of schools was non-random and based on practical considerations. One school distributed letters in 3rd and 4th grades, one school in 5th and 6th grades. The focus groups took place on school grounds, during lunch break or in an after-school child care setting. Making use of the school's lunch or after-school child care settings was an inclusion 
criterion. Only one sibling per family could participate in the same interview. Around 60 letters per school were distributed. Eight to 10 percent of the children agreed to participate. Parental and child informed consent were gathered. Two children were enrolled in the study, but did no longer meet the inclusion criterion at the time of interviewing.

Table 1

Characteristics of Participants

\begin{tabular}{llclll}
\hline Individual interview & Gender & Age & Birth order & Family type & Family size $^{*}$ \\
\hline Ind 1 & Female & 9 & First born & DisabledCh & 2 \\
Ind 2 & Female & 13 & First born & Nuclear & 3 \\
Ind 3 & Male & 12 & Middle born & Nuclear & 3 \\
Ind 4 & Female & 9 & Last born & Nuclear & 3 \\
Ind 5 & Male & 13 & First born & Blended & 2 \\
Ind 6 & Female & 10 & Last born & Blended & 2 \\
Ind 7 & Male & 11 & First born & Nuclear & 4 \\
Ind 8 & Female & 10 & Middle born & Nuclear & 4 \\
\hline Focus group 1 & & & & & 6 \\
\hline F1-1 & Male & 9 & Middle born & Nuclear & 5 \\
F1-2 & Male & 9 & Last born & Nuclear & 2 \\
F1-3 & Female & 10 & First born & Nuclear & 2 \\
F1-4 & Female & 10 & Last born & Single parent & 2 \\
\hline Focus group 2 & & & & Nuclear & 3 \\
\hline F2-1 & Female & 11 & Last born & Blended & 2 \\
F2-2 & Female & 11 & First born & Nuclear & 3 \\
F2-3 & Female & 11 & Middle born & Nuclear & 3 \\
F2-4 & Female & 11 & Last born & & \\
\hline
\end{tabular}

Note. ${ }^{*}$ number of biological children in the nuclear family.

\section{Data Collection}

A semi-structured interview guide was used for both the individual and the focus group interviews addressing the purpose of the study and some non-threatening introductory questions, such as what their hobbies were and what the word "parenting" meant to them. In a second phase, questions were centered on differential parenting behaviors. These were introduced by means of hypothetical vignettes (see Appendix) in which parents manifested different behavior towards one of the siblings compared to the other. The vignettes included information about child and family characteristics associated with PDT, such as gender and biological relatedness. Children were asked to reflect on the vignettes and to provide further examples. The vignettes were pretested in two children to ensure their comprehension and their potential to evoke responses relevant for the aim of the study. In a third phase, questions were centered on the reasons why parental behavior can differ towards siblings and the feelings that can arise in response. Focus groups and individual interviews lasted approximately one hour were tape recorded and transcribed. Children received a small reward for their participation.

All individual interviews were conducted by the same researcher. In the focus groups, a moderator and co-moderator, both researchers on the topic, guided the discussion, and a master student in educational sciences made additional notes to facilitate subsequent transcription and analyses. At the beginning of each interview, a safe environment was created for the children by explaining some ground rules for the interview, such as: (1) There are no right or wrong answers; and (2) There is no need to talk about personal matters. Also, tape 
recording was explained. The procedure was approved by the Ethical Committee of the KU Leuven (University of Leuven).

\section{Research Questions}

Our research questions were the following: (1) Do children report differences in parenting, and on which domains?; (2) How do children explain or justify potential differences in parental treatment?; and (3) What contributes to their experiences of being treated fair or unfair?

\section{Data Analyses}

Interviews were transcribed and analyzed with NVivo7 (QSR NUD*IST Vivo qualitative data analyses software). We used a hybrid approach to analysis, in which deduction from theory is alternated with induction from the data, correspondent to the recommendations by Vaughan (1992). This approach is considered to be appropriate for theoretical elaboration. We want to explore the nature of children's perceptions and we do not intend to make claims on the importance or incidence of these perceptions. It differs from grounded theory methods developed by Glaser and Strauss (as cited in Vaughan, 1992) by using theoretical notions as a starting point, and thus combining the inductive methods from grounded theory with a deductive model.

We used open coding and axial coding. Open codes were given to each paragraph, producing a summary of its content. We then developed a conceptually clustered matrix in which the open codes were clustered into predefined codes and were assigned to categories that reflected the main research questions: (1) differences in parenting behavior; (2) the reasons children described for these differences; and (3) considerations of fairness. The list of predefined codes was developed based on domains of PDT described in the literature and on children's attributions with regard to PDT as defined by Kowal and Kramer (1997). These codes were used as sensitizing concepts. When the predefined code insufficiently captured the meaning of the open code, the open code was added to the coding frame. This was repeated throughout subsequent interviews in a constant comparison procedure. Finally, we engaged in a selective coding process to develop a theoretical framework, for which the identified categories were used as the main building blocks.

After the third family (six interviews), responses indicated repetition and no new codes had to be formed during analyses, which was indicative of saturation (Richards, 2005). Codes of the individual interviews were triangulated with the findings generated from the focus groups. Triangulation revealed small differences in codes between both methods. Similarity in the content between data generated using different methods was deemed sufficient. We will elaborate on the nuances of both methods in the discussion.

Two researchers independently coded all the transcripts and subsequently discussed their codes. When consensus in conceptualization was reached, a peer debriefing strategy was used to increase credibility, in which a third researcher on the topic reviewed the content and meaningfulness of the codes and corrected for potential over- or under- interpretation.

\section{Results}

We combined the categories deducted from the children's responses in a theoretical model, to explain their relations (see Figure 1): (1) In line with literature about covariates of PDT (Jenkins et al., 2003), children use differences in child, family and context characteristics to explain within-family differences in parenting behavior; (2) Children perceive these differences and judge about the fairness; (3) When children can legitimize differences in parenting, within-family differences in parenting are considered equitable, and as such, align 
with child perceptions of "equal treatment". In case of a mismatch between differences experienced and perceptions of "equal treatment", parents are perceived to engage in favoritism; and (4) However, several factors moderate perceptions of fairness, and thus, of equal treatment versus favoritism: the parental attention each child separately receives (direct parenting); the amount of difference in parenting behavior between the children; whether or not the sibling perceives PDT as unfair; whether the child or the sibling receives more benefits (position), and the extent to which the parent is held responsible for engaging in PDT.

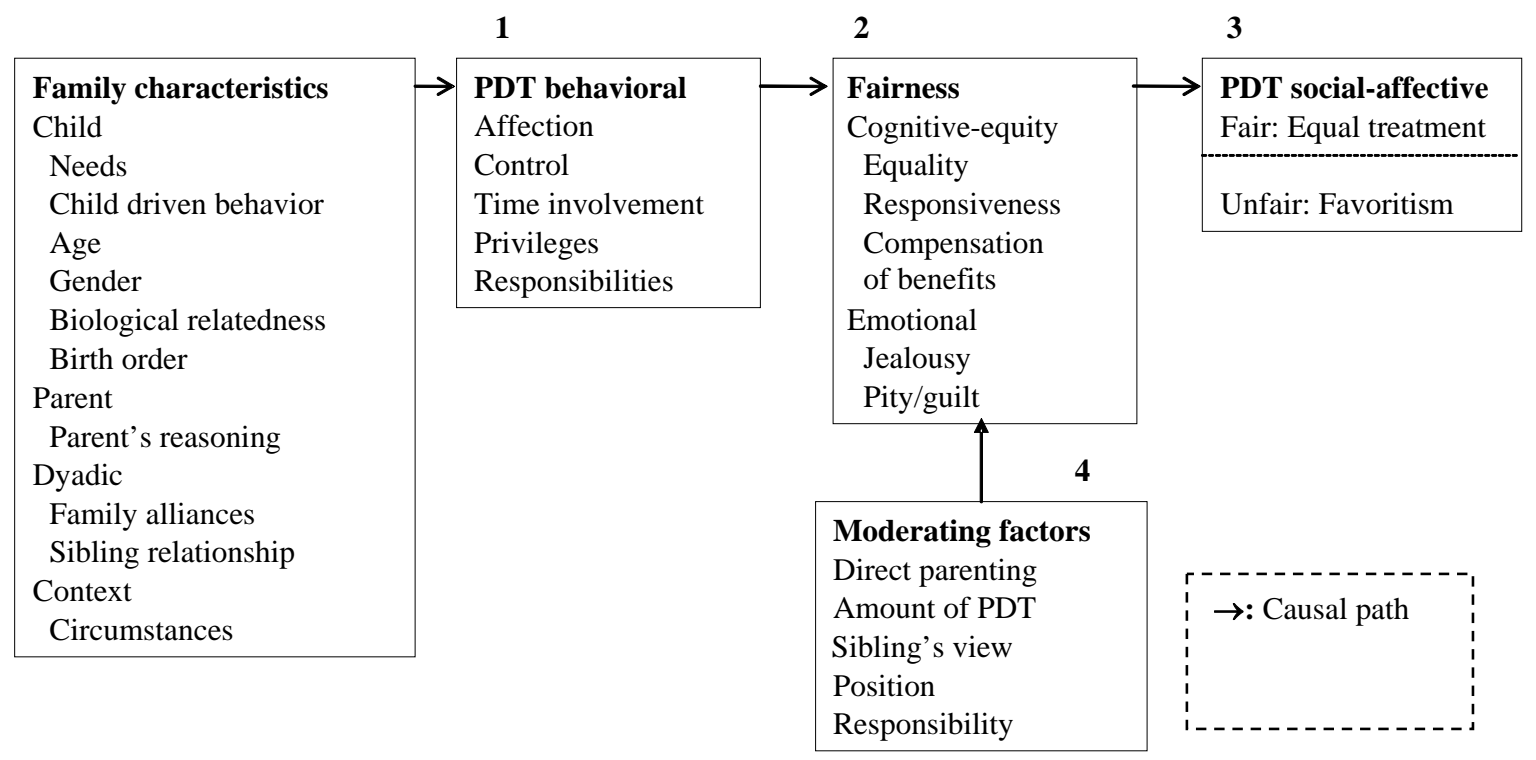

Figure 1. Heuristic model of the concepts in children's perceptions.

In the following section, we describe the different components of the theoretical model and ground them in our data by presenting supporting citations from the interview and focus group excerpts (see Tables 2-5). The causal paths in the model represent a heuristic model on children's representations in this study and we do not claim that there are no bidirectional relationships between certain concepts.

\section{Domains of PDT}

We pre-specified five domains of PDT in our codebook: differences in parental affection, control, time involvement, privileges and household responsibilities (Tucker et al., 2003). Our study revealed no new domains, however, brought sensitivity to its particular content. Supporting citations for the researchers' statements are presented in Table 2.

\section{Affection}

The children in our study reported differences in "physical" expressions of affection, such as giving a goodnight kiss, "verbal" expressions of affection, such as addressing a child with a nickname, and "material" expressions of affection, such as giving a present to the child. They also noticed differences in "praise" in response to a child's performance.

\section{Control}

Children referred to different "rules", for example with regard to the level of independence that was granted, or with regard to bedtime. Also, the "amount” and "severity" of punishment and of reprimands could 
differ between siblings. These differences could be experienced as a difference in parents' strictness.

Table 2

Domains of PDT and Their Specifications

Support/affection. Physical, verbal and material expressions of affection, praise.

F2-3 (girl, 11y, has an older sister): "If my sister has 74\%, it is a huge deal, but when I have $84 \%$...”

Time involvement. Amount of time investment by the parent. Enjoyable activities, task-related activities, interest and priority.

F2-2 (girl, 11y, has a younger brother): I do not like it when my brother has to learn for a test and I do not understand something, because then I ask my mum about it and then she says I have to wait and that she will come to me later on.

Control. Rules, the amount punishment and of reprimands and the severity of punishment.

F2-2 (girl, 11y, has a younger brother): I was not as lively as him when I was his age, and then my mother did not have to be this angry at me, but now my mum has to be angry at him every two days, because he is so hefty and kicks all the time.

Privileges. Enjoyable “extra's”. Social activities, material rewards, rules that were not adjusted to the age of the children.

Ind 2 (girl, 13y, has a younger brother and sister): M. got a mobile phone at an earlier age than I did, I did not like that.

Household responsibilities. Allocation of chores and responsibility of the sibling.

F1-3 (girl, 10y, has a younger sister): I can go alone to the shops but my sister cannot. Now I am allowed to help her. I have to cycle behind her, she can do everything on her own, and I am not allowed to do anything. I have to stand by and look if she can do it. (...) Sometimes, she nags about it, that she cannot go alone. I think it is difficult that we sometimes have to go together, because when something happens, I am responsible.

Children also mentioned sibling conflict in which only one of the children was punished or got reprimands while the other was not. This was experienced as a difference in being blamed by the parent. Children indicated that being strict from time to time was important for the child's development and was an aspect of "good (direct) parenting”.

\section{Time Involvement}

Differential "time involvement" concerns the amount of time the parent invests in the child (Tucker et al., 2003). In our sample, a distinction could be made between "enjoyable activities" between parent and child, such as going on a trip together, and "task-related activities", such as assistance during homework. Although these activities are less enjoyable, children wanted the extra attention. Also, parents could differ in the amount of "interest" they showed in the children's hobbies or activities, for example by attending training sessions. Furthermore, when children simultaneously appealed to the parent, "priority" had to be given and one child could get priority more often than the other.

\section{Privileges}

This reflects that the enjoyable "extra's" children get or are allowed. In our sample, these "extra's" included "social" activities, such as inviting a friend, or "material" goods, such as presents or pocket money. Rules that are "not adjusted to the age" of the children were also experienced as privileges.

\section{Household Responsibilities}

Differential "household responsibilities" are displayed in the allocation of chores. In our sample, the "nature" and "amount" of household chores could differ between children. Further, "taking care of the sibling” was included. Some children had to monitor their sibling, or were considered responsible for their sibling’s behavior.

\section{Favoritism}

Children indicated that, in order not to favor one of their children, parents should spend an equal amount of enjoyable time with each child, that financial resources (presents, clothes...) should be equally divided, that 
each child should have the same opportunity to engage in enjoyable activities (e.g., friend comes over to play, going to a birthday party, number of friends a child can invite to a party), that a parent should not indulge more into one child's wishes than into another, that parents should offer the same amount of physical affection and that they express equal amounts of pride towards their children and interest in the child's activities. Children should have a comparable stake in chores. When a child has a conflict with the sibling, the parent must not take the side of the sibling. These answers show the relevance of the jealousy evoking situations identified in previous research and illustrate that children can experience favoritism in all domains of PDT. Further, they reflect both equal parenting behavior (e.g., amount of enjoyable time), as well as equal adaptation of parents towards child characteristics (e.g., indulgence in children's wishes).

\section{Children's Explanations of PDT}

\section{Specification of the Categories Originally Identified by Kowal and Kramer}

We used the categories identified by Kowal and Kramer (1997) as a starting point in the analyses. We added three new categories to the children's explanations: biological relatedness, sibling relationship and birth order. Supporting citations for all categories are presented in Table 3.

Child's needs. PDT is a consequence of a parent's responsiveness to the needs of the child or the sibling (Kowal \& Kramer, 1997). Child responses in our sample reflected "physical” needs (e.g., illness and sleep), "psychological” needs (e.g., fears and social acceptance) and “cognitive needs” (e.g., help with study).

Child-driven behaviors. Children attribute PDT to self-governed behavior of the child (Kowal \& Kramer, 1997). The answers of the children in our sample included "positive" and "problematic" child behavior, in which they mentioned severity and frequency as components, to which the parent responds. Furthermore, "intentionality" of the child to provoke a certain parental response was taken into account. In these examples of intentional child-driven behavior, the child was held responsible for PDT, and not the parent.

Age. Children attribute PDT to the age disparity between siblings (Kowal \& Kramer, 1997). Several rules are related to age, such as time of bed, or going out alone. In our sample, children took into account "developmental level and developmental stage” (childhood versus adolescence). With regard to developmental level, the child's safety was mentioned. With regard to developmental stage, they mentioned increased disparity between parents' and adolescents' goals, and increased concordance in interests and cognitive capacity. What also emerged was the expectation that the child will receive similar treatment/favoritism when he/she reaches the age of the sibling.

Personal attributes. The "personal attributes" category of Kowal and Kramer (1997) refers to differences in personality traits or characteristics between children, to which the parent responds. In our study, children mentioned personality as a broad category, as well as more specific aspects. Answers go back to "compliance" and children's "feelings" (self-confidence and irritability). Another category is "interests", which are related to the child's wishes or "desires".

Family alliances. Children attribute PDT to positive relationships between a parent and child or to a dyadic family structure in which each child feels closer to a different parent (Kowal \& Kramer, 1997). Our sample described closer dyadic relationships based on "mutuality", such as mutual interests (that could be related to gender), gender and goals/desires. Children also distinguished whether the preference was "located" in the parent or originated in the child. Parental preference was considered less fair than child preference. Children also indicated that family alliances could "change" over time. 
Table 3

Children's Explanations of PDT

Specification of the categories originally identified by Kowal and Kramer (1997)

Needs. Physical needs (e.g., illness and sleep), psychological needs (e.g., fears and social acceptance) and cognitive needs (e.g., help with study).

F2-3 (girl, 11y): I have to go to bed earlier, not because I am younger, but because I have a disease on my muscles and if I go to bed at a later hour, I cannot get up in the morning and then it bothers me the next day.

Child driven behaviors. Positive and problematic child behavior, to which the parent responds. The child can intend to provoke a certain parental response.

Ind 5 (boy, 13y, has a younger sister): My sister will always look for a way to go to bed at the same time as me. My mum pays close attention to that and says it is time to go to bed. Then she (sister) says "yes, I am almost ready, I just have to finish something" and then she is watching TV again and then she forgets about it.

Age. Age disparity between siblings. Children take into account developmental level and developmental stage (childhood versus adolescence).

F2-1 (girl, 11y, has an older sister): If they (parents) want to talk, then my sister is gonna be their favorite, because she can be more serious and she can think by herself more. (...) I think it is OK, because in the future, that is gonna be me.

Personal attributes. Personality as a broad category, as well as more specific aspects, such as compliance, feelings, interests, wishes or desires.

F2-2 (girl, 11y, has a younger brother): At our place, it is not really "each at his own turn", but it depends on whether it is something I like or my brother likes.

Going to the fire station, my brother enjoys. Going to the musical, thàt my brother was not into, but I could come along, because I really wanted to see it.

Family alliances. Close dyadic relationships between family members. These can be based on mutuality, or on preference.

Ind 1 (girl, 9y): It depends on who they prefer to play with. If they prefer to play with the dad and the other one prefers the mum, then yeah, I think it is normal that the mum plays more with him and dad with her. But if it is the other way around, than they should alternate, or if they both love one person, but that is almost impossible, then they should alternate.

Circumstances. Practical considerations that are placed outside the characteristics of the family members or of their dyadic relationships.

Researcher: Is it OK, if a parent goes on a trip more often with one child than with the other, or does it have to be the same?

Child (Ind 7, boy, 11y, has three younger siblings): More or less two at a time, because it is easiest.

Gender. Child gender or parent-child gender constellation.

Ind 2 (girl, 13y): My friend's mother told just now that boys keep pushing and get their way, because parents do not like it that they nag all the time.

Parent's reasoning. A consideration of the parent, with which the child can agree or disagree. Parents can also have incorrect or absent information, and children describe arbitrariness of parental behavior.

F2-4 (girl, 11y, has an older sister): When my parents are in a bad mood, they are often mad at my sister, and then she does nothing wrong and they send her upstairs. Then she cannot have candy, and then my brother and I bring her candy.

Inequality. Children equate fairness with exact equality and do not take into account other characteristics that can legitimize differences in parents' behavior.

Ind 1 (girl, 9y, has a disabled sibling): ..., or it is brother's birthday party, and he can ask more friends than the sister, then she will think it is unfair.

Additional categories

Biological relatedness. PDT because of differences in biological relatedness to the parent.

Ind 5(boy, 13y, blended family): I do not think the stepparent should punish. The one that has to punish, is the real parent.

Sibling relationship. PDT is attributed to characteristics of the sibling relationship.

F1-1 (boy, 9y, has 3 older brothers and sisters): ... if one child gets pushed by the other to come along, than that younger child should not really be punished, because it got pushed by the older brother or sister.

Birth order. Differences in birth order, regardless of age difference.

F2-1 (girl, 11y, has an older sister): When my sister was in sixth grade, she was allowed much less, because she's the oldest and has to take responsibility for us.

Now she still has to take responsibility for us. 
Circumstances. Circumstances comprise uncontrollable or incidental causes (Kowal \& Kramer, 1997). In our sample, these could be captured as practical considerations that are placed outside the characteristics of the family members or of their dyadic relationships. Children described some practical issues leading to differences, such as the amount of schoolwork, or hobbies interfering with activities.

Gender. This category addressed alliances between parents and children, because they share the same gender (Kowal \& Kramer, 1997). Children in our sample distinguished between "gender-related interests", which can lead to same-gender-alliances and "parent's preference" for a specific gender. Parental preference was considered less fair than alliances because of mutuality. Children however also referred to differences in child "behavior" which are gender-related. This explanation is independent of the parent's gender.

Parent's reasoning is faulty. PDT is attributed to a consideration of the parent (Kowal \& Kramer, 1997). This can be viewed as unfair parent-driven behavior. Likewise, children could also express faith in the parent's reasoning, which was apparent in our sample. According to children, parents can also have incorrect or absent "information". Children described "arbitrariness" of parental behavior, for example because of the parent's mood.

(In)equality. Children focus on exact equality of the parental behavior (Kowal \& Kramer, 1997). Interestingly, even when faced with a clear expression of differential treatment, as provided in the vignettes, in some instances children denied there was a difference in the parent's behavior. Their reflections could more closely be captured as a refutation of the existence of a difference than as a legitimization of the difference.

\section{Additional Categories}

In our design, we included a hypothetical vignette that contained information about biological relatedness and our sample showed variation in family type. Furthermore, children's answers suggested considerations with regard to the sibling relationship, so we also directed our attention to sibling factors.

Biological relatedness. Children indicated that step-parents may not have the "mandate" to discipline non-biological children. It was not their task, and the biological parents could be angry about the stepparent's interference. In this regard, children could also differ in compliance towards biological versus non-biological parents and only listen to the biological parent. On the other hand, children referred to a lesser degree of "engagement" in non-biological parent-child relationships. The stepparent could be unwilling to direct certain behaviors towards a non-biological child. Interestingly, these responses also emerged from children who grew up in nuclear families.

Sibling relationship. Children attributed differences in power and responsibility in the sibling relationship, often related to age disparity. This included active "power assertion" as well as "modeling". In this way, an older child could be responsible for misbehavior of a younger child, leading to differences in parents' strictness.

Birth order. An age-related factor is birth order. Children attributed more responsibility to earlier born children. Therefore, it might be useful to distinguish birth order from the mere developmental aspects of age.

\section{Principles of Fairness}

Fairness is a multidimensional concept. Legitimacy of parental treatment does not exclude negative affective reactions (Ihinger, 1975; McHale \& Pawletko, 1992). Children can agree with parents' reasons for differential treatment, but still crave the benefits the sibling receives. Likewise, children can disagree with the unbeneficial treatment of the sibling, but not feel any sympathy. In our sample, children expressed 
understanding when siblings got more parental attention, but also indicated feeling less important at that moment. Within the attribution of fairness, there is still a lot of ambivalence. In our description, we distinguished between cognitive aspects and emotional aspects of fairness. Supporting citations for our theoretical concepts are presented in Table 4.

Table 4

Principles of Fairness

Cognitive component

Equality. Children focus on equality of parenting behavior or deny difference in PDT vignettes.

Ind 1 (girl, 9y, has a disabled sibling): (in response to vignette 3) Maybe the stickers belong to Rozelien ánd Bart, that’s also possible, and that they both collect stickers, and that Rozelien gets some other stickers, and then Bart does not. And, yeah, that it is for one and the same sticker book.

Responsiveness. Responsiveness to child characteristics. Responsiveness is contrasted to arbitrariness and parental preference. Ind 5 (boy, 13y, blended family): Again, there are two possibilities: or, Nick is not allowed to come along and is shifted aside a bit by his father, or, Nick does not want to come along and maybe has a lot of homework to do and is a bit older and is not interested in that.

Compensation. The parents or sibling compensate for parental attention/benefits one sibling receives over another, concurrently or by taking turns.

Ind 4 (girl, 9y, has an older brother and sister): My sister does not inherit any clothes from another sister, but I do, so I have more clothes than her, so she gets more new clothes.

Emotional component

Jealousy. Expressions that the treatment of the sibling is preferred.

F2-3 (girl, 11y, has a younger brother and an older sister): I understand it but I do not like it. I can hear my brother still having fun, while I am already in bed.

Guilt. Expressions of feeling guilty towards the sibling because of one's own preferential parental treatment.

L: Klaas (favored child in vignette 4) will probably feel guilty.

Pity. Expressions of feeling sympathy for the sibling because of the sibling's treatment.

F2-3 (girl, 11y, has an older sister): Sometimes, when I really think it is unfair, then I feel sorry for my sister, but other times, I think "so what, it is her own fault. What goes around and comes around".

\section{Cognitive Component}

Several principles of distributive justice reasoning are clearly recognizable in children's explanations. Children could focus on exact "equality" of the parental behavior. However, parents could also adapt their behavior to differing child characteristics. Children mentioned "responsiveness" to children's differing preferences and interests, self-governed behavior, age and developmental tasks, needs, power differences in the sibling relationship, biological relatedness and compliance towards the parent. Children acknowledged parental goals and expressed faith in their parent's reasoning.

Responsiveness is contrasted to arbitrariness - for example, punishment should depend on the severity of the misbehavior, and not on the parent's mood—and to a parent's preference for one sibling.

Another means to acquire equitable treatment was if the parent compensated for differences in behavior. This "compensation" could be by repeating similar behavior to the sibling in the future, which adheres to turn-taking, or by equating the benefit on another parenting domain. In this way, the difference was eliminated. Not only the parent could fulfill this function: Children also referred to the sibling, for example by sharing a gift that was given to one of them, or to the other parent, for example when one parent goes on a trip with one child, and the other parent does an enjoyable activity with the other. 


\section{Emotional Responses}

We searched for expressions of preference with regard to position (jealousy, pity and guilt). Children indicated that they could feel "jealous" in response to differential treatment, even if they understood their parents' motives for PDT. Children indicated jealousy when the sibling received more beneficial treatment. Children also expressed feelings of "guilt" and "pity" on the part of the favored child.

\section{Moderating Factors}

Several factors moderated perceptions of fairness (see Table 5). First, the "level of direct parenting" was taken into account. If parents expressed a high degree of affection and/or a low degree of punishment, differences were more tolerable. Second, the "amount of difference" ought to be small. Third, "the view of the sibling" moderated fairness. They took into consideration whether the sibling is or is not bothered by differences in parental behavior (whether the sibling believes the PDT is fair). Fourth, judgments about fairness could differ, if they themselves had the preferred "position" compared to the situation where the position of sibling was more favorable. Fifth, children made attributions about "responsibility". The sibling could be held responsible for the difference in treatment, intentionally evoking a certain parental response. When children considered parental treatment unfair, they could also express diminished responsibility of the parent for his/her behavior, for example because of emotional state.

Table 5

Moderating Factors of Fairness

Direct parenting. The characteristics of the individual parent-child relationship each child has with the parent.

Ind 3 (boy, 12y, middle born): If they do not get punished a lot, and then one gets punished a bit more, then I would not mind.

Amount. The amount of difference, whether it is small or large.

Ind 4 (girl, 9y, has an older brother and sister): I think the difference is too much. What they did wrong differed, but even though...

Sibling's view. Children take into consideration whether the sibling is or is not bothered by differences in parental behavior (whether the sibling believes the PDT is fair). In this, characteristics of the sibling relationship are taken into account.

Ind 3 (boy, 12y): It depends on how bothering this is to Rozelien (“unfavored” child in vignette 3).

Position. Judgments about fairness can differ if the child has the preferred position compared to the sibling.

F2-2 (girl, 11y): If it is (more strictness) towards you, it is not OK, if it is towards the other, it is.

Responsibility. Judgments about the amount of responsibility for PDT.

Ind 6 (girl, 10y, has an older brother, blended family): Maybe, mum had a bad day at work, and she does not want to say too much...

\section{Discussion}

The aim of this study was to clarify the concept of PDT in children in middle and late childhood, by focusing on children's perceptions of fairness. In a qualitative design in which we centered questions about PDT around hypothetical vignettes, we aimed to increase our understanding of the nature of the differences siblings perceive, their explanations for differences in parenting behavior and their considerations of fairness. We expanded principles of distributive justice to parental attention, a socially relevant context for children in middle and late childhood. The domains, attributions and covariates identified in the literature on PDT were used as sensitizing concepts, in order to refine and complement them when appropriate (Vaughan, 1992).

\section{Main Findings}

Children provided further examples of the different domains of PDT-affection, control, privileges, 
household responsibilities and time involvement (Daniels \& Plomin, 1985; Tucker et al., 2003). These domains are defined quite general in literature. Our sample allowed further refinement, such as distinguishing between pleasurable and task-related activities in parents' differential time involvement. In line with research of Koch (as cited in McHale et al., 2000) that first and second born children differ in family responsibilities, we included responsibility of the sibling as an aspect of household responsibilities. Also, children expressed ambiguity with regard to direct parental control, viewing both its beneficial aspects for development and its token of parental involvement, as well as the unpleasantness of the confrontation with boundaries. This supports the relevance of the fine-tuning of measurements of differential parental control, in which control currently is valued negatively (Sheehan \& Noller, 2002).

Social relations between characters influence distributive justice reasoning (McGillicuddy-De Lisi et al., 2008). This finding might be extended to biological relatedness between family members. Children viewed non-biologically related parent-child relationships as less engaged and the parent is ascribed less authority. This is in line with research of O'Connor, Hetherington, and Clingempeel (1997), indicating that relationships are significantly more interconnected in intact families compared to stepfamilies in the early stages of remarriage. Further, Thomson et al.'s (1992) showed that stepmothers direct less positive and less negative behavior towards stepchildren, suggesting a lower level of engagement rather than a more negative relationship with stepchildren. These patterns are also apparent in stepfathers (DeGarmo \& Forgatch, 2007). Less cohesive relationships in stepfamilies can be adaptive. O'Connor et al.'s (2006) research shows that biological relatedness was associated with differential parenting and independent of child problem behavior.

Kowal and Kramer (1997) were pioneers in tracking down children's explanations of PDT, which can be captured within distributive justice reasoning. In these explanations, we can delineate some salient characteristics, such as age and gender. Although current differences in parental behavior can seem more apparent to children (Kowal et al., 2002), children in our study paid specific attention to the age on which a certain rule was set. They took into consideration if rules applied to them at the same age of the sibling.

Further, parents respond to differing needs, which is in line with the benevolence-rule. Parents reacting on child (mis)behavior might reflect the equity-rule. The positive associations between referring to the sibling's need and sibling relationship quality, as evident in the research of Kowal and Kramer (1997) can be related to the use of the benevolence-rule, which is more evident in a family context and testifies of a higher level of distributive justice reasoning (Thomson \& Jones, 2005). Future quantitative research should target the associations between the contents and fairness-ratings and investigate whether benevolence can be applied in other contents. For example, as children distinguish between birth order and developmental aspects of age, some instances of legitimizing PDT by referring to age differences might be illustrations of benevolence.

Besides a cognitive component of fairness, reflecting distributive justice reasoning, this study also showed the importance of an emotional component of fairness attributions, and specification of the categories uncovered information relevant to dimensions of attributions. Attribution theory considers cognitive judgements about the causes of situations. Attributions refer to: (1) specific "contents"; or (2) underlying "dimensions" of these contents that can be the topic of investigation (Weiner, Graham, \& Chandler, 1982). The attributions described above are at a content level. These contents, however, differ in certain dimensions. Several causal dimensions are described in attribution literature: locus, which can be intern or extern to the attributor; stability, or whether the cause will influence similar situations in the future; globality, or whether the cause will influence other situations; and controllability, or whether the cause is perceived as controllable by 
self or others (Weiner \& Graham, 1984). In interpersonal situations, Fincham, Beach, Arias, and Brody (1998) also described dimensions of responsibility attributed to the persons in the interaction - intent, selfish motivation and blame. Attributions are linked to affective and behavioral reactions. According to Boll et al. (2003), siblings can develop angry feelings towards the parent, when they hold that the parent is responsible for PDT.

Different loci could be retrieved from children's responses. Explanations for PDT could be assigned to the character, the sibling, or the parent. A family alliance could be based on a preference located in the parent or in the child. Children could hold expectations of future PDT, which adheres to stability. Further, they made nuances in responsibility - a sibling can intentionally or unintentionally evoke certain treatment and parents can choose to treat their children differently or can be the object of circumstances or misunderstandings. Differences in causal and responsibility dimensions might explain how certain attributions are linked to family relationships and individual well-being. For example, referring to a sibling's need might excuse the sibling (and the parent) from getting preferred treatment. Identifying the characteristics on these dimensions that contribute to positive child outcome can be a direction for future research.

\section{Strengths and Limitations of the Current Study}

Our method differed from previous research in two ways. First, we included children belonging to different family types. Second, we placed questions about PDT in a general family context. Both are aimed to increase the scope of children's perceptions. We do not intend to make claims on the importance of the categories, only of their existence, nor do we want to compare children who belong to different family contexts. Future quantitative research is needed to target these questions.

Whereas Kowal and Kramer (1997) started from children's personal experiences of PDT within their family, by elucidating reflections after children's responses to a questionnaire, we structured the interviews around hypothetical vignettes. Hypothetical vignettes have been used as an introduction to the SIDE, to reduce reluctance in children to report PDT (Kowal et al., 2002) and in research on distribution of household chores (Thomson, 2007). In western society, “equal treatment” is an important general value (Parsons, 1974). Our sample expressed both positive and negative feelings concerning this treatment. Also, children were able to reflect on causes of PDT that were not applicable to their own family situation. For example, children of nuclear families provided information about non-biological parent-child relationships. Thus, the vignettes increased intra-individual variation in responses.

We used predefined concepts as sensitizing concepts in our subsequent inductions. A priori knowledge and conceptualizations can narrow the researcher's view in inductive analyses (Glaser \& Strauss, 1967). However, in line with Vaughan (1992), we argue that it might be advisable to identify the underlying theories that drive the researcher's induction rather than to assume that the researcher is a "tabula rasa", without predefined knowledge.

We triangulated our methods using individual interviews and focus groups. There were some nuances. Differences in fairness with regard to the child's position - favored versus unfavored as a moderator of fairness - was an important topic in the first focus group. Further, although both methods revealed sibling relationship quality as an explanation for PDT, they displayed different characteristics of the sibling relationship. In the focus groups, children referred to differences in power between siblings. Children in the individual interviews indicated that parents react to conflict between siblings and want their children to get along well. Thus, although the individual interviews indicated saturation, focus groups added slightly different 
information. It is possible that we stopped data-collection prematurely. Another explanation could be that the children in focus groups felt that they could respond more general to the topic, creating possibilities for responses that are not limited by issues of family loyalty or social desirableness. In our view, the combination of both methods contributed to the richness of the data.

We do not claim that our categorization is exhaustive. We did not include children residing in foster families, adolescents or clinical populations. The focus groups in our study were homogeneous only with regard to developmental level of the participants. Groups can also be composed based on homogeneity in gender or family type. Questions to children in blended families can specifically target the relationship with the non-biological parent. Also, children's views on PDT can be contrasted to parents' views.

Response rates for focus group participation were quite low. This is partly because of the study's inclusion criterion. Besides practical reasons, parents may be reluctant to participate in parenting research. They might fear that their children reveal too much private information about their family situation. Children can be unwilling to participate because of personal characteristics, such as shyness. Thus, the sample might be limited to well-functioning families and to children with better verbal and social skills.

\section{References}

Boll, T., Ferring, D., \& Filipp, S. H. (2003). Perceived parental differential treatment in middle adulthood: Curvilinear relations with individuals' experienced relationship quality to sibling and parents. Journal of Family Psychology, 17, 472-487.

Crick, N. R., \& Dodge, K. A. (1994). A review and reformulation of social information-processing mechanisms in children's social-adjustment. Psychological Bulletin, 115, 74-101.

Daniels, D., \& Plomin, R. (1985). Differential experience of siblings in the same family. Developmental Psychology, 21, 747-760.

DeGarmo, D. S., \& Forgatch, M. S. (2007). Efficacy of parent training for stepfathers: From playful spectator and polite stranger to effective stepfathering. Parenting: Science and Practice, 7, 331-355.

Deutsch, M. (1975). Equity, equality, and need—What determines which value will be used as basis of distributive justice. Journal of Social Issues, 31, 137-149.

Donley, M. G., \& Likins, L. (2010). The multigenerational impact of sibling relationships. The American Journal of Family Therapy, 38, 383-396.

Dunn, J., \& Munn, P. (1985). Becoming a family member-Family conflict and the development of social understanding in the 2nd Year. Child Development, 56, 480-492.

Dunn, J., Stocker, C., \& Plomin, R. (1990). Nonshared experiences within the family: Correlates of behavioral problems in middle childhood. Development and Psychopathology, 2, 113-126.

Fearon, R. M. P., van IJzendoorn, M. H., Fonagy, P., Bakermans-Kranenburg, M. J., Schuengel, C., \& Bokhorst, C. L. (2006). In search of shared and nonshared environmental factors in security of attachment: A behavior-genetic study of the association between sensitivity and attachment security. Developmental Psychology, 42, 1026-1040.

Feinberg, M. E., McHale, S. M., Crouter, A. C., \& Cumsille, P. (2003). Sibling differentiation: Sibling and parent relationship trajectories in adolescence. Child Development, 74, 1261-1274.

Fincham, F. D., Beach, S. R. H., Arias, I., \& Brody, G. H. (1998). Children’s attributions in the family: The children's relationship attribution measure. Journal of Family Psychology, 12, 481-493.

Glaser, B. G., \& Strauss, A. L. (1967). The discovery of grounded theory: Strategies of qualitative research. New York: Aldine.

Ihinger, M. (1975). Referee role and norms of equity-contribution toward a theory of sibling conflict. Journal of Marriage and the Family, 37, 515-524.

Jenkins, J. M., Rasbash, J., \& O’Connor, T. G. (2003). The role of the shared family context in differential parenting. Developmental Psychology, 39, 99-113.

Kennedy, C., Kools, S., \& Krueger, R. (2001). Methodological considerations in children’s focus groups. Nursing Research, 50, $184-187$. Kowal, A., \& Kramer, L. (1997). Children's understanding of parental differential treatment. Child Development, 68, 113-126.

Kowal, A. K., Krull, J. L., \& Kramer, L. (2004). How the differential treatment of siblings is linked with parent-child relationship quality. Journal of Family Psychology, 18, 658-665. 
Kowal, A. K., Krull, J. L., \& Kramer, L. (2006). Shared understanding of parental differential treatment in families. Social Development, 15, 276-295.

Kowal, A., Kramer, L., Krull, J. L., \& Crick, N. R. (2002). Children’s perceptions of the fairness of parental preferential treatment and their socioemotional well-being. Journal of Family Psychology, 16, 297-306.

McGillicuddy-De Lisi, A. V., De Lisi, R., \& Van Gulik, K. (2008). The effects of grade level, context, and family type on male and female adolescents' distributive justice reasoning. Journal of Adolescence, 31, 107-124.

McGuire, S., Dunn, J., \& Plomin, R. (1995). Maternal differential treatment of siblings and children’s behavioral problems—A longitudinal study. Development and Psychopathology, 7, 515-528.

McHale, S. M., Crouter, A. C., McGuire, S. A., \& Updegraff, K. A. (1995). Congruence between mothers and fathers differential treatment of siblings-Links with family-relations and children's well-being. Child Development, 66, 116-128.

McHale, S. M., \& Pawletko, T. M. (1992). Differential treatment of siblings in 2 family contexts. Child Development, 63, 68-81.

McHale, S. M., Updegraff, K. A., Jackson-Newsom, J., Tucker, C. J., \& Crouter, A. C. (2000). When does parents' differential treatment have negative implications for siblings? Social Development, 9, 149-172.

Morgan, D. L. (1996). Focus groups. Annual Review of Sociology, 22, 129-152.

O’Connor, T. G., Dunn, J., Jenkins, J. M., \& Rasbash, J. (2006). Predictors of between-family and within-family variation in parent-child relationships. Journal of Child Psychology and Psychiatry, 47, 498-510.

O’Connor, T. G., Hetherington, E. M., \& Clingempeel, W. G. (1997). Systems and bidirectional influences in families. Journal of Social and Personal Relationships, 14, 491-504.

Parsons, T. (1974). Age and sex in social structure. In R. L. Coser (Ed.), The family: Its structures and functions (pp. 243-255). New York: St. Martins. (Originally published in American Sociological Review, 7, 604-616).

Plomin, R., \& Daniels, D. (1987). Why are children in the same family so different from one another. Behavioral and Brain Sciences, 10, 1-16.

Plomin, R., Asbury, K., \& Dunn, J. (2001). Why are children in the same family so different? Nonshared environment a decade later. Canadian Journal of Psychiatry-Revue Canadienne de Psychiatrie, 46, 225-233.

QSR International Pty Ltd.. (2006). NVivo (Qualitative data analysis software) (Version 7).

Richards, L. (2005). Handling qualitative data: A practical guide. London, Sage.

Schaefer, E. S. (1959). A circumplex model for maternal behavior. Journal of Abnormal and Social Psychology, 59, $226-235$.

Shanahan, L., McHale, S. M., Crouter, A. C., \& Osgood, D. W. (2007). Warmth with mothers and fathers from middle childhood to late adolescence: Within-and between-families comparisons. Developmental Psychology, 43, 551-563.

Sheehan, G., \& Noller, P. (2002). Adolescents’ perceptions of differential parenting: Links with attachment style and adolescent adjustment. Personal Relationships, 9, 173-190.

Tamrouti-Makkink, I. D., Dubas, J. S., Gerris, J. R. M., \& van Aken, M. A. G. (2004). The relation between the absolute level of parenting and differential parental treatment with adolescent siblings' adjustment. Journal of Child Psychology and Psychiatry, 45, 1397-1406.

Thompson, J. A., \& Halberstadt, A. G. (2008). Children's accounts of sibling jealousy and their implicit theories about relationships. Social Development, 17, 488-511.

Thomson, N. R. (2007). Justice in the home: Children's and adolescents' perceptions of the fair distribution of household chores. Journal of Moral Education, 36, 19-36.

Thomson, N. R., \& Jones, E. F. (2005). Children's, adolescents' and young adults' reward allocations to hypothetical siblings and fairness judgments: Effects of actor gender, character type, and allocation pattern. The Journal of Psychology, 139, 349-367.

Thomson, E., McLanahan, S. S., \& Curtin, R. B. (1992). Family-structure, gender, and parental socialization. Journal of Marriage and the Family, 54, 368-378.

Tucker, C. J., McHale, S. M., \& Crouter, A. C. (2003). Dimensions of mothers' and fathers' differential treatment of siblings: Links with adolescents' sex-typed personal qualities. Family Relations, 52, 82-89.

Vaughan, D. (1992). Theory elaboration: The heuristics of case analysis. In C. Ragin \& H. S. Becker (Eds.), What is a case? Exploring the foundations of social inquiry (pp. 173-202). Cambridge, UK: Cambridge University Press.

Weiner, B., \& Graham, S. (1984). An attributional approach to emotional development. In C. E. Izard, J. Kagan, \& B. Zajonc (Eds.), Emotions, cognition and behavior (pp. 167-191). Cambridge, England: Cambridge University Press.

Weiner, B., Graham, S., \& Chandler, C. (1982). Pity, anger, and guilt-An attributional analysis. Personality and Social Psychology Bulletin, 8, 226-232. 


\section{Appendix: Hypothetical Vignettes}

Vignette 1-Rules. Robbe and Seppe are brothers. Robbe goes to bed every night at $20 \mathrm{~h}$, Seppe at $20 \mathrm{~h} 30$. Before they go to bed, mum and dad give them both a goodnight kiss.

Vignette 2-Punishment. Els and Bart had a tough day at school: they both got a remark from their teacher. Els did not hand in her homework, Bart had a fight with his friend. Mum and dad are not pleased. Els has to copy her homework, Bart is not allowed to watch TV or play computer games for two days.

Vignette 3-Reward. Bart learns to study by himself. Every day, he has to make one task at his own. If he does well, he gets a set of stickers at the end of the week. Rozelien does her homework by herself. She does not get stickers at the end of the week, but she gets a big hug from mum and dad.

Vignette 4-Time involvement. The dad of Nick and Klaas arrives home, and has something nice to tell: The neighbours have a new dog! His name is Basiel, and he is a five-year old Labrador. Dad takes Klaas along to have a look, Nick stays at home.

Vignette 5-Gender. It is weekend. On Saturday, mum takes Evelien along to the city, to buy clothes for her Holy Communion. On Sunday, Joost goes to a football match with his father.

Vignette 6-Biological relatedness. Ann and Mathilde are half-sisters. Mathilde only joins the family during weekends. On Friday, they both hand in a bad school report. Mum gives Ann a punishment, she has to study an hour each day during the weekend. Mum sends Mathilde to her room until dad arrives.

Vignette 7-Sibling conflict. Mum arrives home from work. Gert and Joke are fighting downstairs about a toy. Mum tells Gert to play with something else upstairs. Joke keeps on playing with the toy downstairs. 